\title{
A!
}

This is an electronic reprint of the original article.

This reprint may differ from the original in pagination and typographic detail.

Jämsä-Jounela, Sirkka-Liisa; Vapaavuori, E.; Salmi, T.; Grönbärj, M.; Vermasvuori, M.

\section{Fault diagnosis system for the Outokumpu flash smelting process}

Published in:

IFAC PROCEEDINGS VOLUMES

DOI:

10.1016/S1474-6670(17)37033-7

Published: 01/01/2000

Document Version

Peer reviewed version

Please cite the original version:

Jämsä-Jounela, S-L., Vapaavuori, E., Salmi, T., Grönbärj, M., \& Vermasvuori, M. (2000). Fault diagnosis system for the Outokumpu flash smelting process. IFAC PROCEEDINGS VOLUMES, 431-436.

https://doi.org/10.1016/S1474-6670(17)37033-7

This material is protected by copyright and other intellectual property rights, and duplication or sale of all or part of any of the repository collections is not permitted, except that material may be duplicated by you for your research use or educational purposes in electronic or print form. You must obtain permission for any other use. Electronic or print copies may not be offered, whether for sale or otherwise to anyone who is not an authorised user. 


\title{
FAULT DIAGNOSIS SYSTEM FOR THE OUTOKUMPU FLASH SMELTING PROCESS
}

\author{
S-L. Jämsä-Jounela ${ }^{(1}$, E. Vapaavuori ${ }^{(1}$, T. Salmi ${ }^{(1}$, M. Grönbärj ${ }^{(1}, M^{-} \operatorname{Vermasvuori}^{(1}$
}

${ }^{1)}$ Laboratory of Process Control and Automation, Aalto University

\begin{abstract}
Fault diagnosis systems have attracted growing interest in a number of engineering fields. The number of applications has increased and successful results have been widely reported. This paper presents and outlines a fault diagnosis system for flash smelting. The system monitors the states of the process by means of Kohonen Self-Organising Maps and performs the fault diagnosis of the process equipment by analysing the operation of the process equipment. Finally the results of the off-line testing of the system are reported and discussed.
\end{abstract}

Keywords: Fault diagnosis, Kohonen Self-Organising Maps, inference, Rete, flash smelting

\section{INTRODUCTION}

Process monitoring and fault diagnosis have been widely studied and reported in recent years. A large number of industrial applications are reviewed e.g. in Isermann et al. (1997). The systems have been developed to lower the operating costs of a process and to improve the working conditions by making the plant environmentally safe.

As presented in Iserman (1997) and Stephanopoulos et al. (1996), the integration of different process monitoring and fault diagnosis methods is important when all forms of knowledge must be captured and utilized. According to Iserman et al. (1997), both classification and rule-based reasoning methods are the most important monitoring and diagnosis methods.

Experimentally trained classification methods are applied in fault diagnosis if no information is available about the fault-symptom causalities (Iserman et al., 1997). Kohonen Self-Organizing Maps (Kohonen, 1988) have proved to be an effective method for classifying and visualising high dimensional data in engineering applications. Otsuka et al. (1992) and Lassus et al. (1998), classified the wall temperatures of a blast furnace by SOM. SelfOrganising Maps have also been applied in analysing the hot rolling of steel (Simula et al., 1999). Excellent results were also obtained when SOM was applied in the classification of ore type in the feed of a concentrator (Jämsä-Jounela et al., 1998).

If the fault-symptom causalities can be expressed in the form if-then rules reasoning method can be used for fault diagnosis (Isermann et al., 1997). The Rete algorithm, developed by Forgy (1982), is widely recognized to be the most efficient algorithm in the implementations of production systems and it is the only algorithm whose efficiency is asymptotically independent of the number of rules (Haley 1996). In the Rete -algorithm, efficiency is obtained by remembering the past test results across the iterations of the rule loop. The Rete -algorithm has been used in a number of expert system shells like OPS5 (Forgy, 1982), CLIPS (Riley, 1999) and JESS (Friedman-Hill, 2000).

However, the process monitoring and fault diagnosis methods have not yet been applied in development of large scale industrial systems for metallurgical industry. The aim of this paper is to outline and present a fault diagnosis system for the Outokumpu flash smelting process.

Analysis of the Outokumpu flash smelting process was performed as a preliminary study in the project. Disturbances and equipment failures at two copper smelters were studied by Vapaavuori (1999) using statistical methods and principal component analysis. 


\section{OUTOKUMPU COPPER FLASH SMELTING}

Outokumpu flash smelting is a pyro metallurgical process for smelting metal sulphide concentrates. The Outokumpu flash smelting process consists of a flash furnace, waste heat boiler and electrostatic precipitator. A flash smelter usually also includes the following auxiliary units: feed mixture preparation and drying, converters, slag treatment system, $\mathrm{SO}_{2}$ fixation system, anode furnace and anode casting. A more detailed description can be found in Vapaavuori (1999).

\section{FAULT DIAGNOSIS SYSTEM FOR FLASH SMELTING}

The fault diagnosis system for the Outokumpu flash smelting process monitors the states of the process, and also performs fault detection and diagnosis on the process equipment. If abnormalities in the states of the process or condition of the process equipment are detected, the system suggests suitable recovery actions to the process operators. The system can also provide information for production planning and maintenance. The integrated system is composed of modules such as process data bases, a process state classification, symptom generation, process equipment data base, a rule-base of decision rules, decision making and a user interface.

The classification module classifies the type of feed material and monitors the states of the process in every process section using Kohonen Self-Organising Maps. The classification results are passed to a symptom generation module where they are evaluated against the criteria that determinate the location of the different process states on the Kohonen Maps of each process section.

Fault detection is performed on the process equipment on the basis of the symptoms and knowledge stored in the rule base and process equipment knowledge base. Symptoms are generated on a symptom generation module by comparing the process data with the predefined criteria of abnormal operation. In the current system the method used in symptom generation from process data are limit- and binary-value checking.

In a decision making module the monitoring of process states and fault detection on the process equipment are performed simultaneously. This reveals possible interactions between process abnormalities and equipment failures. The decisionmaking module is composed of inference engine, unit process data base, rule-base and user interface. The inference engine application of the system utilises forward chaining with the Rete -algorithm as its reasoning strategy. The results of inference are presented via the user interface and recorded on a log file.
The prototype fault diagnosis system for Outokumpu flash smelting runs under the windows NT operating system. The process state classification and symptom generation modules of the application are programmed using java. The process equipment data and rule-base are stored in a Microsoft SQL-Server. The inference engine application is developed with the Java Expert System Shell and the user interface built using Java Swing Components. The system is outlined in Figure 1.

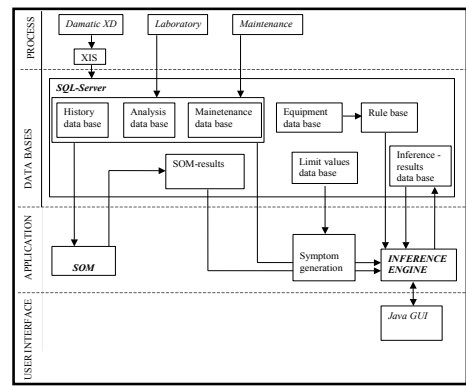

Fig. 1. Fault diagnosis system

\section{KOHONEN SELF ORGANISING MAPS}

In SOM each neuron, $i$, is represented by an $\mathrm{n}$ dimensional weight vector, $m_{i}=\left[m_{i 1}, \ldots, m_{i n}\right]^{T}$, where $\mathrm{n}$ is equal to the dimension of the input vectors. The weight vectors of the SOM form a codebook. In each training step, one sample vector $\mathrm{x}$ is taken randomly from the input data set, and a similarity measure is calculated between the vector and all codebook vectors. The Best-Matching Unit is the codebook vector with the shortest distance to the input vector. The $B M U$ is defined in Alhoniemi et al. (1996) as:

$\left\|x-m_{c}\right\|=\min _{i}\left\{\left\|x-m_{i}\right\|\right\}$

Where $\|$.$\| is the measure of the distance. When BMU$ is found, the weight vectors in SOM are updated. The SOM update rule for the weight vector of the unit $i$ is, according to Alhoniemi et al. (1996),

$m_{i}(t+1)= \begin{cases}m_{i}(t)+\alpha(t)\left\lfloor x(t)-m_{i}(t)\right\rfloor, & i \in N_{c}(t) \\ m_{i}(t) & , \quad i \notin N_{c}(t)\end{cases}$

Where $t$ is the time, $x(t)$ is the randomly selected input vector from the input data at time $t, N_{c}(t)$ is the non-increasing neighbourhood function around the winner unit $c$. The distribution of the data in the map is evaluated by calculating the number of hits of every process state as percentages of the total number of hits in each neurone. It can be presented as follows:

$H I T_{-} A_{i j}=\frac{100 \cdot(\text { state })_{i j}}{(\text { total })_{j}}$ 
Where total $_{j}$ is the total number of hits in the neurone $j$ and state $_{i j}$ is the total number of hits in a neurone $j$ due to the abnormal process state $i$. How the hits of the process states are distributed within their own map regions was also calculated. This distribution is calculated using the following formula:

$H I T_{-} C_{i j}=\frac{100 \cdot(\text { state })_{i j}}{(\text { state })_{i}}$

Where state $_{i j}$ is the total number of hits in the neurone $j$ due to a process state $i$ and $s t_{j i}$ is the total sum of hits of that state $i$.

\section{ANALYSIS OF PROCESS STATES AND DISTURBANCES}

In this study the SOMs were trained using the data collected from a copper smelter during a ten-month period. The data were pre-treated by manually removing incorrect measurement values from the data set. The values collected during shutdowns were also removed. After the pre-treatment, the data were scaled by the mean-centering and autoscaling techniques. In mean-centering the mean of each variable is subtracted from each observation, and autoscaling refers to dividing each variable by its standard deviation, each scaled variable having a variance of unity.

The maps were trained to classify different states in the sub-systems of the process. The subsystems analysed in more detail in the beginning were the type of feed material and respective control strategy, and the condition of the gas line on the basis of the pressure distribution in the process.

\subsection{Classification of feed material type}

Different control strategies for the furnace should be selected on the basis of the chemical composition of the feed material. The chemical composition of the feed material may increase the probability that specific faults will occur. The chemical composition of the feed material is analysed from the concentrate samples taken after the dryer. The total number of variables was 8 and of samples 631 . The variables were: arsenic, zinc, lead, copper, iron, sulphur, silicon and calcium. At the start of the feed material analysis the data were divided into 7 groups according to the theoretical set point value of the oxygen enrichment coefficient. Each group was also labelled with the set point value that it represented. The division of the data is presented in Table 1.
Table 1 Data groups and number of data points

\begin{tabular}{ccc}
\hline GROUP & CRITERION & NUMBER OF POINTS \\
\hline 1 & $>190$ & 71 \\
2 & $180-190$ & 130 \\
3 & $170-180$ & 97 \\
4 & $160-170$ & 148 \\
5 & $150-160$ & 124 \\
6 & $140-150$ & 49 \\
7 & $<140$ & 12 \\
\hline
\end{tabular}

The original data were then used to train the SOM and, after training, it was analysed whether the data formed clusters that were representing the groups of the set point values. The SOM for feed material classification is presented in Figure 2.

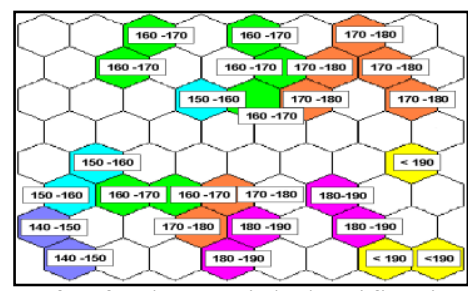

Fig. 2. SOM for feed material classification

The distribution of the data in the map was evaluated using Eqs. 3 and 4. Eq. 3 was used to locate the different areas of set points in the SOM. The neurone in SOM was selected to represent a specific set point if the number of hits in the neurone was above $70 \%$. The analysis showed that the data were scattered in the lower right hand corner of the map when the set point values were high. At low set point values the data were located at the upper left-hand corner of the map. The scattering of the data according to Eqs. 3 and 4 is presented in Tables 2 and 3.

Table 2 Number of hits of set points

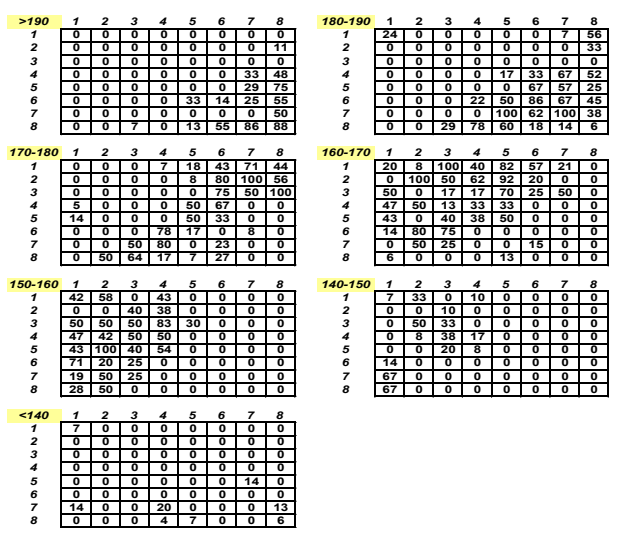


Table 3 Distribution of the hits in map regions

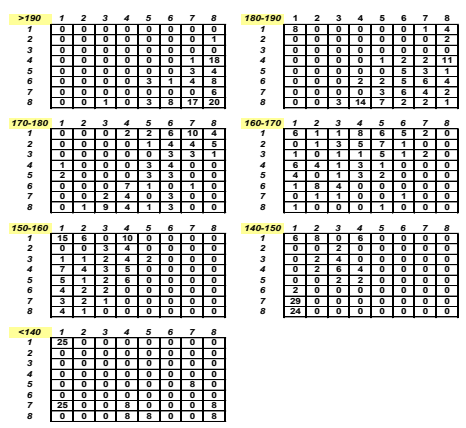

There are blank areas in the map where the data groups are located on the top of each other and these must be re-evaluated.

\subsection{Monitoring of the condition of the gas line}

The pressure distribution in the process gives information about excessive dust evolution and the formation of dust aggregations. Dust aggregations in the waste heat boiler may cause failures in the materials of the process units and they were therefore analysed in detail. The data set used in the analysis had the following 7 variables: pressure in the furnace, pressure in the waste heat boiler, pressure in the gas line, position of the gas hood, rotation speed of the gas blower, vibration of the gas blower and pressure in the acid plant. The total number of data points used in the analysis was 5000. The data contained information about the process under normal operation, shooting, excessive vibration of the gas blower, and excessive dust evolution, and it was therefore divided into four groups and labelled accordingly. The data groups and number of data points are presented in Table 4.

Table 4 Data groups and number of data points

\begin{tabular}{clc}
\hline GROUP & \multicolumn{1}{c}{ CRITERION } & NUMBER OF POINTS \\
\hline- & Normal & 2723 \\
1 & Shooting & 469 \\
2 & $\begin{array}{l}\text { Excessive vibration of } \\
\text { the gas blower }\end{array}$ & 493 \\
3 & $\begin{array}{l}\text { Excessive dust evolution } \\
\text { and aggregation }\end{array}$ & 1315 \\
\hline
\end{tabular}

The original data were used to train the SOM and, after training, it was analysed whether the data formed clusters according to the operating condition of the process. The distribution of the data in the map was evaluated using Eqs. 3 and 4. The neurone in SOM was selected to represent a specific operation condition if the number of hits in the neurone was above $70 \%$. The SOM for the pressure distribution is presented in Figure 3.

The analysis showed that the neurones indicating shooting were located at the higher left hand corner of the map, with the neurones for excessive dust aggregation located below it. During excessive vibration of the gas blower two clusters of process data were formed and were located at the lower left and higher right hand corner of the map. 11 neurones out of a total 64 could not be classified directly into a specific class. These neurones were scored by the process data representing both shooting and dust evolution, dusting and normal operation, and vibration of the gas blower and normal operation.

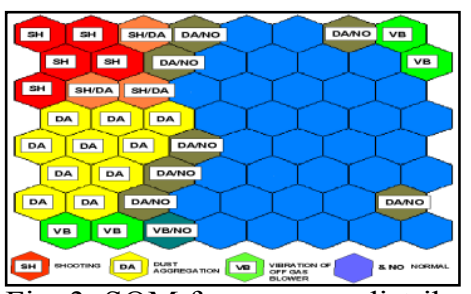

Fig. 3. SOM for pressure distribution

How the hits of the process states are distributed within their own map regions was also calculated using the $\mathrm{Eq} 4.88 \%$ of the total number of hits scored by the values of normal operation were located within the map area of normal operation. More than $70 \%$ of the hits scored by the vibration of the gas blower and shooting were also located in their own areas. $38 \%$ of the hits scored by the data representing excessive evolution of flue dust were located on the map area of dust evolution, and 5 and $17 \%$ in the transition areas of shooting and dust evolution and dust evolution and normal operation, respectively. The scattering of the data according to Eqs. 3 and 4 are presented in Tables 5 and 6.

\section{Table 5 Number of hits of set points}

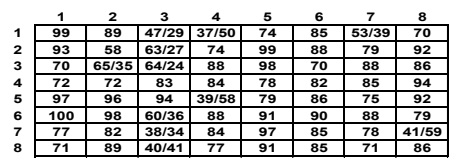

Table 6 Distribution of the hits in map regions

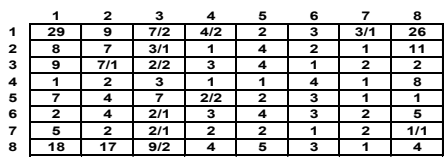

There are areas in the map where the data groups are overlapping because the process is shifting gradually from normal operation into the abnormal state, and the point in time of the origin of the abnormal state can therefore not, in most of the cases, be explicitly expressed.

The Kohonen Self -Organising Maps proved to be an effective tool in measurement classification and in monitoring the process conditions. The results are reviewed in more detail in Salmi (1999). The analysis will be continued in the future in order to extend and improve the monitoring capabilities of the system. The main emphasis will be on studying feature extraction on the basis of the analysis of the process trends. 


\section{RESULTS OF THE ANALYSIS OF THE PROCESS EQUIPMENT}

In the proposed system for flash smelting the faults in the process equipment are also detected. The decision about the condition of the steam dryer is performed on the basis of the process state classification and fault detection on the process equipment. The system was tested at a copper flash smelter on a multi-coil steam dryer that is used in drying the feed material of a flash furnace. At the smelter both heuristic knowledge and numerical data were collected. Knowledge about the operation of the multi-coil steam dryer was obtained from the plant personnel and the operation reports of the smelter. This knowledge was used to identify the most important operational problems of the dryer and to design a strategy for diagnosing the condition of the process equipment.

The numerical data for testing the system were collected during a five-month period. The data consisted of one-hour averages of process measurements. The operational problems of the dryer reported during the testing period were the clogging of the off gas filter and excessive flue dust emissions. The data set used in testing had the following 9 variables: amounts of process gas, steam and feed material, pressure differences in the off gas filter and between the drier and off gas line, vibration in the off gas blower, noise level in the drier, load of the electrical drive and temperature of the lubrication oil in the electrical drive.

When testing the system the steam dryer process was divided into units such as the electrical motor that rotates the steam coil, body of the dryer and filter and blower of the off gas. Temperature, noise level and pressure measurement instruments were also connected to process units. All the units of the multicoil steam dryer process are handled in the system as objects and they contain rule bases of the units and information about the name, variables and connections of the units. The inference engine automatically builds the Rete -network on the basis of the rules stored in rule bases. All the units in the system have a rule base of their own, and subsequently also Rete -networks of their own. The steam dryer process used in testing is presented in Figure 4 a). The Rete -networks for the process equipment and measurement instruments are presented in Figure $4 \mathrm{~b}$ ).

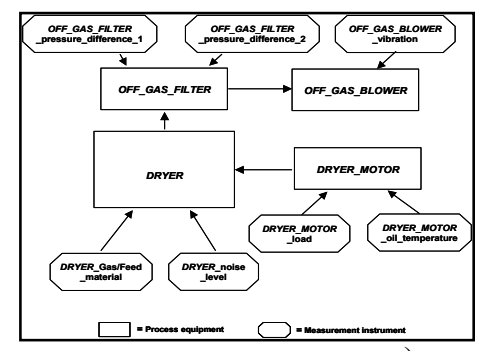

a)

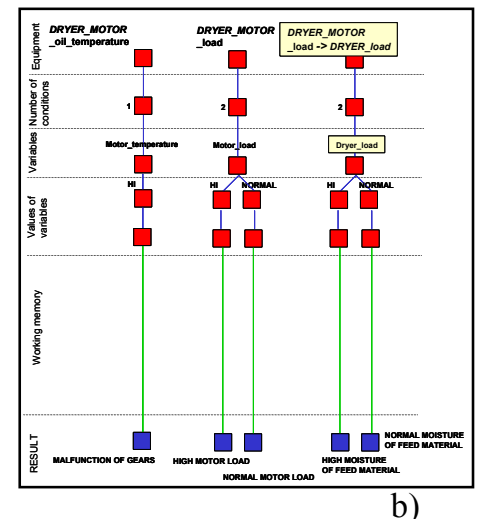

Fig. 4. a) Flow sheet of the testing system for the multi-coil steam dryer and b) Rete -networks

The system detected failures and also found possible reasons for failures to a satisfactory level of accuracy. The most important disturbances in the process during the testing period were caused by problems in controlling the amount of process gas with respect to the dried concentrate-flux mixture. If the amount of process gas is low with respect to the amount of concentrate, then the moisture content of the off gas is too high and the off gas filter is clogs due to flue dust aggregations. At the end of the observation period the fault diagnosis system frequently warned about clogging of the off gas filter and excessive vibration of the off gas blower. The results are reviewed in more detail in Grönbärj (1999). The description of the inference engine is presented in Figure 5, using the example where an equipment failure "filter is clogging" occurred. The failure was generated by a control problem "low level of nitrogen in the process gas".

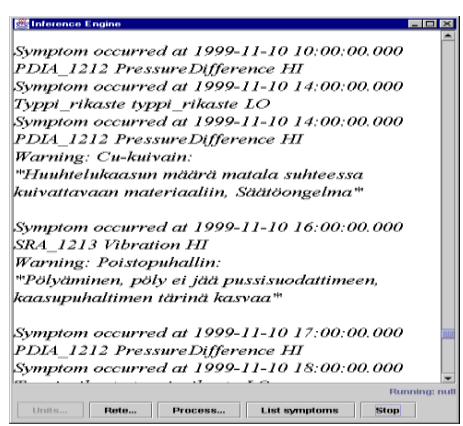

Fig. 5. Inference engine of the system.

The inference engine utilising forward chaining with the Rete-algorithm as its reasoning strategy operated well and effectively in diagnosing failures in the multi-coil steam dryer. The inference engine will be tested on line in the near future and the operation of the engine will be extended to cover the whole flash smelting process.

\section{CONCLUSIONS}

Process monitoring and fault diagnosis have been widely studied in recent years. However, the methods 
have not been applied in the metallurgical industry for developing large-scale industrial systems dedicated to both process monitoring and fault diagnosis of process equipment. The aim of this paper was therefore to outline and present a fault diagnosis system for the Outokumpu flash smelting process.

The structure of the fault diagnosis system is outlined and presented. The system is integrated, and it monitors the states of the process and performs fault detection and diagnosis on the process equipment The integrated system is composed of modules such as process data bases, process state classification, symptom generation, a process equipment data base, a rule base of decision rules, decision making and a user interface. In the system the classification is performed by SOM and the decision making utilising forward chaining with the Rete -algorithm as its reasoning strategy.

The fault diagnosis system is giving promising results in both process monitoring and detection of the condition of process equipment failures. A prototype of the system will be implemented and tested as an industrial application in the near future. The main emphasis in testing will be on the integrated features of the process monitoring and fault diagnosis of the process equipment, and the use of a combination of the two in decision making.

\section{ACKNOWLEDGEMENT}

The authors would like to acknowledge the plant personnel for their support while collecting the data for the paper.

\section{REFERENCES}

Alhoniemi, E., J. Hollmén, O. Simula, and J. Vesanto, J. (1999). Process Monitoring and Modelling Using Self-Organising Map. Integrated-Computer-Aided-Engineering, vol. 6, no. 6 , pp. 3-14

Forgy, C. L. (1982). Rete: A Fast Algorithm for the Many Pattern/Many Object Pattern Match Problem, Artificial Intelligence, vol. 19, pp.17-37.

Friedman-Hill, E-J. (2000). Jess, the Java Expert System Shell, http://herzberg.ca.sandia.cov/jess/

Gröbärj, M. (2000), Inference Methods in Industrial Fault Diagnosis, Master of Science (Tech.) Thesis, HUT.

The Haley Enterprise (1996), The Rete Algorithm, $<$ http://www.haley.com/>

Iserman, R. (1997), Supervision, Fault-Detection and Fault-Diagnosis Methods- an Introduction, Control. Eng. Practice, vol. 5, no. 5, pp. 639-652.

Iserman, R. and P. Balé (1997). Trends in the Application of Model Based Fault Detection and Diagnosis of Technical Processes, Control. Eng. Practice, vol. 5, no. 5, pp. 709-719.
Jämsä-Jounela, S-L., S. Laine, and E., Ruokonen (1998). Ore Type Based Expert System in Mineral Processing Plants, Part. Part. Sys. Charact., vol. 15, pp. 200-207.

Kohonen, T. (1988). The Self-Organizing Map. Proceedings of the IEEE, Vol. 78, p. 1464-1480.

Lassus, L. and H. Saxén (1998). Tool for Classification of Blast Furnace Wall Temperatures. Preprints of the IFAC MMM'98, pp. 277-281.

Otsuka, Y., K. Hanaoka, M. Konishi (1992). Applications of Neural Network Models to Iron and Steel Making Processes, Proceedings of the 2nd International Conference on Fuzzy Logic and Neural Networks, pp. 815-818.

Riley, G. (2000). A Tool for Building Expert Systems, http://www.ghg.net/clips/CLIPS.html

Salmi, T. (1999), Fault Diagnosis System for Flash Smelting, Master of Science (Tech.) Thesis, HUT.

Simula, O., Alhoniemi, E., Himberg, J. and Vesanto , J. (1999), Self-Organising Maps in Analysis of Large Industrial Systems, Kohonen Maps, Elsevier, pp. 375-387.

Stephanopoulos G. and C. Han (1996). Intellingent Systems in Process Engineering a Review. Computers chem. Engng, vol. 20, pp. 743-791.

Vapaavuori, E. (1999), Performance Monitoring of the Outokumpu Flash Smelting Process Through Principal Component Analysis. Licentiate thesis, HUT. 